\title{
Antinuclear autoantibodies are more prevalent in COPD in association with low body mass index but not with smoking history
}

\author{
H P J Bonarius, ${ }^{1,6}$ C A Brandsma, ${ }^{1}$ H A M Kerstjens, ${ }^{2}$ J A Koerts, ${ }^{1}$ M Kerkhof, ${ }^{3}$ \\ E Nizankowska-Mogilnicka, ${ }^{4}$ C Roozendaal, ${ }^{5}$ D S Postma, ${ }^{2}$ W Timens ${ }^{1}$
}

'Department of Pathology and Medical Biology, University Medical Center Groningen, University of Groningen, The Netherlands

${ }^{2}$ Department of Pulmonology, University Medical Center Groningen, University of Groningen, The Netherlands ${ }^{3}$ Department of Epidemiology and Statistics, University Medical Center Groningen, University of Groningen, The Netherlands

${ }^{4}$ Department of Pulmonology, Jagiellonian University Medical College, Cracow, Poland ${ }^{5}$ Laboratory Center University Medical Center Groningen, University of Groningen, The Netherlands

${ }^{6} \mathrm{OO}$ Therapeutics, Groningen, The Netherlands

\section{Correspondence to} Professor Dr W Timens, Department of Pathology and Medical Biology, University Medical Center Groningen, University of Groningen, Hanzeplein 1, 9713 GZ Groningen, The Netherlands; w.timens@path.umcg.nl

Received 7 January 2010 Accepted 26 August 2010 Published Online First 3 November 2010

\begin{abstract}
Background Chronic obstructive pulmonary disease (COPD) is associated with a higher prevalence of antinuclear autoantibodies (ANAs). However, a significant subgroup of patients is ANA negative. It remains to be determined which patient groups carry autoantibodies.
\end{abstract}

Methods The association of smoking behaviour, disease status, gender, age and body mass index (BMI) with the presence of autoantibodies in the serum was determined in 124 patients with COPD and 108 non-COPD control subjects. In addition, the role of $B$ cells in autoantibody generation in COPD was investigated by sequencing the antibody repertoire of $B$ cells in the lungs of patients with COPD and of ex-smoking and never-smoking control subjects.

Results Patients with COPD had a significantly higher risk of being serum positive for ANAs (OR 3.12, 95\% CI 1.68 to $5.76, p<0.001)$. ANAs were not significantly associated with age, smoking status, gender or packyears of smoking. Within the COPD population, subjects with $\mathrm{BMI}<22 \mathrm{~kg} / \mathrm{m}^{2}$ had a significantly higher risk of ANAs (OR 4.93, 95\% Cl 1.50 to $16.50, p=0.009$ ) than those with normal or high BMI. The antibody repertoire of $B$ cells in the lungs of patients with COPD had a high frequency of positively charged CDR3 residues, a feature which is associated with self-reactive antibodies.

Conclusion The results show that COPD is a heterogeneous disease with respect to the prevalence of ANAs. ANAs are primarily associated with the presence of COPD and with low BMI, but not with smoking and forced expiratory volume in $1 \mathrm{~s}$.

\section{INTRODUCTION}

Chronic obstructive pulmonary disease (COPD) is a widespread disease. In the USA alone, 15-25 million people $(5-10 \%$ of the population) are affected. ${ }^{1} 2$ Despite its high and increasing prevalence and mortality, the pathogenesis of COPD remains unclear and there is no effective treatment available that halts the irreversible and progressive tissue destruction and small airway wall fibrosis which are characteristic of the disease.

The immune system is chronically activated in COPD. Markers of systemic inflammation such as $\mathrm{C}$ reactive protein and interleukin 6 are present in stable COPD and their levels relate to disease severity. ${ }^{3}$ Additionally, inflammatory cells are increased in different areas of the lung. The percentage of small airways containing neutrophils and B cells increases with disease severity, as defined by Global Initiative for Chronic Obstructive Lung Disease (GOLD) criteria. ${ }^{4}$ Furthermore, there are more $B$ cells in the large airways of patients with COPD with GOLD stage III compared with GOLD stage II. ${ }^{5}$ Lymphoid follicles consisting of B cells and follicular dendritic cells with adjacent $T$ cells have been demonstrated in the parenchyma and in bronchial walls of patients with emphysema, ${ }^{6}$ and are present in the small airways in patients with severe and very severe COPD. ${ }^{4}$ We previously identified the presence of ongoing somatic mutations in the majority of these follicles, suggesting oligoclonal antigen-specific proliferation. ${ }^{6}$

Studies showing increased levels of antinuclear antibodies (ANAs) ${ }^{7} 8$ indicate an antigen-specific self-reactive response in patients with COPD. In addition, increased levels of anti-elastin autoantibodies and Th1 responses against elastin have been found in emphysema. ${ }^{9}$ This suggests the presence of antibody-mediated degradation of extracellular matrix which might contribute to sustained inflammation. Other papers reported no evidence for systemic autoantibodies directed against elastin peptides in chronic inflammatory lung disease. ${ }^{10} 11$ About $70 \%$ of patients with COPD were positive for ANAs, ${ }^{8}$ suggesting heterogeneity in the autoimmune response in COPD. In addition, serum samples of patients with COPD show a variety of ANA patterns (antinucleolar, centromeric, speckled), possibly reflecting reactivity against different antigens.

It is not yet clear which factors determine this heterogeneity. Age, gender and smoking have all been shown to have an effect on the prevalence of ANAs in the general population. ${ }^{12}$ However, these relations have not been investigated in COPD. We therefore investigated which patient characteristics (ie, smoking behaviour, gender, age, lung function and physical characteristics) determine the presence of (antinuclear) autoantibodies in COPD. In addition, as the increased numbers of $B$ cells found in COPD lung tissue are likely to be involved in the generation of autoantibodies, we also analysed the antibody repertoire (immunoglobulin heavy chain) of lung tissue-derived B cells from patients with COPD and non-COPD controls.

\section{METHODS \\ Lung tissue}

Human lung tissue was obtained from surgical resection material of eight patients with COPD and eight without the disease. ${ }^{13}$ In case of tumours, 
only lung tissue distant from the tumour was included. Tissue from patients with severe emphysema was obtained from lung resections in case of single or double lung transplantation or lung volume reduction surgery. COPD was confirmed by the combination of forced expiratory flow in $1 \mathrm{~s}\left(\mathrm{FEV}_{1}\right)$ and $\mathrm{FEV}_{1} /$ forced vital capacity (FVC) ratio following GOLD criteria, ${ }^{14}$ and the presence of emphysema was based on histological examination of lung tissue performed by an experienced pulmonary pathologist (WT).

\section{Serum analysis}

A total of 232 serum samples were analysed for ANAs. Samples were derived from patients with COPD without $(n=30)$ and with $(\mathrm{n}=94)$ a history of smoking and control subjects with normal lung function without $(\mathrm{n}=37)$ and with $(\mathrm{n}=71)$ a history of smoking. Age and gender were matched whenever possible in these four subject groups The majority of the samples were obtained from two population-based studies-the European Community Respiratory Health Study (ELON) ${ }^{15}$ (84 samples) and the Burden Of Lung Disease (BOLD) ${ }^{16}$ (68 samples). Fifty-seven samples were obtained from a previous study which included agematched controls ${ }^{17}$ and 23 samples were obtained from patients with COPD undergoing lung transplantation. Patients with asthma were excluded. None of the subjects had signs or symptoms of any autoimmune disease. All subjects were characterised by lung function, smoking status and smoking history (packyears). Smoking status was indicated as never-smoker or eversmoker, the latter including current and former smokers. Age, gender, height and weight were known for all subjects, except for the BOLD study where weight was not recorded.

\section{Autoantibody analysis}

Serum levels of three types of autoantibodies were measured: ANAs, antineutrophil cytoplasm autoantibodies (ANCAs) and antibodies against other tissue antigens (anti-mitochondrial, anti-smooth muscle, anti-parietal cell and anti-liver-kidney microsomal).

Indirect immunofluorescence (IIF) was performed to screen for ANAs according to standard routine diagnostic procedures as used at the Laboratory for Clinical Immunology, University Medical Center, Groningen, The Netherlands. A commercial kit (HEp2000 IFA kit, ImmunoConcepts, Sacramento, California, USA) was used according to the guidelines of the manufacturer's specifications. For screening purposes, the ANA measurements were performed in two different dilutions (1:40 and 1:80). Serum samples that were positive in this screening assay were retested in twofold dilutions ranging from 1:40 to 1:640. This means that all positive samples were tested in duplicate. Serum samples with a titre of $\geq 1: 80$ were considered positive. ${ }^{18}$ Fluorescence patterns were reported as homogeneous, coarse speckled, fine speckled, nucleolar or the anti-SSA pattern that is typical of Hep2000 cells.

ANCAs directed against myeloperoxidase (anti-MPO antibodies) were determined by ELISA as described previously. ${ }^{19}$ IIF was performed to screen for antibodies against other tissue antigens according to standard routine diagnostic procedures as used for detection of anti-mitochondrial, anti-smooth muscle, anti-parietal cell and anti-liver-kidney microsomal autoantibodies at the Laboratory for Infectious Diseases, Groningen, The Netherlands. ${ }^{18}$

\section{Analyses of $\mathrm{IgH}$ repertoire of $B$ cells isolated from human lung tissue}

CD20-positive B cell follicles were harvested from $20 \mu \mathrm{m}$ thick frozen sections by laser microdissection (PALM GmbH, Bernried,
Germany). The IgH repertoire was then determined by PCR, cloning of the PCR pools in $E$ coli and sequencing as described previously. ${ }^{6}$ Annotation of IgH CDR3 (length, translation, DH and $\mathrm{JH}$ families) was performed with V-Quest open access software. ${ }^{20}$

\section{Statistical analysis}

A two-sided Fisher exact test was used to test the statistical significance of contingency tables. The two-tailed Mann-Whitney test was used for testing statistical significance of differences between the frequency of positively charged CDR3 amino acid residues.

ORs and $95 \%$ CIs for the association between the presence of ANAs and several independent variables were calculated using logistic regression analysis. The associations were studied univariately and after adjustment for age, gender, smoking, BMI, COPD status or country of residence if the variable was a confounder. A confounder was defined as a variable whose removal from the model caused a change in the estimated coefficient of at least $10 \%$ in multiple logistic regression analysis.

BMI was entered into the logistic regression model as a dichotomous variable defining 'low BMI' as $<22 \mathrm{~kg} / \mathrm{m}^{2}$. This provided the best goodness of fit using Akaike information criteria compared with models with BMI as a continuous variable or as a categorical variable $(<22,22-24,24-26,26-28$ and $\geq 28 \mathrm{~kg} / \mathrm{m}^{2}$ )

Statistical testing was performed at a significance level of $p=0.05$. SPSS software Version 14.0 was used for statistics.

\section{RESULTS \\ Participant characteristics}

Table 1 shows the characteristics of never-smokers and eversmokers among subjects with and without airway obstruction. The never-smoking COPD patient group contained significantly more women and were older than the other groups and generally had less severe COPD compared with the COPD ever-smoker group.

\section{Effect of smoking, COPD (severity), gender, age and lung function on the presence of ANAs}

Figure $1 \mathrm{~A}$ shows that significantly more patients with COPD than controls were serum positive for ANAs ( $44 \%$ vs $22 \%$, $\mathrm{p}=0.001)$. This difference between COPD and non-COPD controls remained significant in subgroups of never-smokers (14/ 30 ANA-positive in COPD group vs 7/37 in non-COPD group; $\mathrm{p}=0.019)$ and of ever-smokers (40/94 ANA-positive in COPD group vs $17 / 71$ in non-COPD group; $\mathrm{p}=0.013$ ). Within the COPD group there was no significant difference in the percentage positive for ANAs between never-smokers and eversmokers $(p=0.833)$.

The median titre in both the ANA-positive COPD group and the ANA-positive control group was 1:80. The most frequently observed fluorescence pattern was coarse speckled ( $81 \%$ of patients with COPD and $80 \%$ of controls), although other samples showed a nucleolar pattern.

Table 2 shows the univariate and adjusted ORs for ANAs for the independent variables analysed. COPD significantly increased the probability of being ANA-positive (OR 3.12, 95\% CI 1.68 to 5.76). Gender, age and smoking status had no significant effect on the presence of $\mathrm{ANAs} . \mathrm{FEV}_{1} \%$ predicted, $\mathrm{FEV}_{1} / \mathrm{FVC}$ ratio and pack-years of smoking had no relationship with the presence of ANAs (table 2). 
Table 1 Characteristics of participants

\begin{tabular}{|c|c|c|c|c|}
\hline & Healthy never smokers & Healthy ever smokers & COPD never smokers & COPD ever smokers \\
\hline \multicolumn{5}{|c|}{ (A) Grouped by disease status and smoking history } \\
\hline Subjects (n) & 37 & 71 & 30 & 94 \\
\hline Women (\%) & 54.1 & 45.1 & 80.0 & 36.2 \\
\hline Age (years) & $55.9 \pm 8.5$ & $55.7 \pm 9.3$ & $68.1 \pm 10.3$ & $60.4 \pm 7.3$ \\
\hline $\mathrm{FEV}_{1} \%$ pred & $112.6 \pm 20.3$ & $101.2 \pm 16.1$ & $73.0 \pm 20.7$ & $58.8 \pm 23.2$ \\
\hline $\mathrm{FEV}_{1} / \mathrm{FVC}(\%)$ & $81.7 \pm 5.1$ & $77.5 \pm 6.2$ & $56.5 \pm 15.2$ & $56.3 \pm 11.6$ \\
\hline Current smokers (\%) & - & 46.5 & - & 46.8 \\
\hline \multirow[t]{2}{*}{ Pack-years smoking } & 0 & $29.6 \pm 39.6$ & 0 & $36.9 \pm 18.7$ \\
\hline & Healthy normal BM & Healthy low BMI & COPD normal BMI & COPD low BMI \\
\hline \multicolumn{5}{|c|}{ (B) Grouped by disease status and body mass index (BMI). } \\
\hline Subjects (n) & 55 & 6 & 68 & 16 \\
\hline BMI $\left(\mathrm{kg} / \mathrm{m}^{2}\right)$ & $26.3 \pm 3.3$ & $20.9 \pm 0.6$ & $26.8 \pm 3.4$ & $21.1 \pm 1.3$ \\
\hline Women $(\%)$ & 40.0 & 66.7 & 33.8 & 50.0 \\
\hline Age (years) & $56.4 \pm 7.2$ & $53.3 \pm 4.1$ & $60.0 \pm 6.9$ & $59.9 \pm 7.8$ \\
\hline $\mathrm{FEV}_{1} \%$ pred & $110.8 \pm 17.5$ & $108.2 \pm 5.9$ & $56.4 \pm 21.5$ & $52.3 \pm 22.6$ \\
\hline $\mathrm{FEV}_{1} / \mathrm{FVC}$ ratio $\times 100$ & $80.6 \pm 6.0$ & $79.5 \pm 6.4$ & $55.5 \pm 12.2$ & $54.4 \pm 8.4$ \\
\hline Pack-years smoking & $14.7 \pm 14.9$ & $16.8 \pm 10.5$ & $36.3 \pm 20.5$ & $34.6 \pm 18.0$ \\
\hline
\end{tabular}

Values are expressed as percentage or mean $\pm S D$.

$\mathrm{BMI}$, body mass index; COPD, chronic obstructive pulmonary disease; $\mathrm{FEV}_{1} \%$, forced expiratory volume in $1 \mathrm{~s}$ (\% predicted); FVC, forced vital capacity.

\section{Effect of BMI and disease on autoantibodies}

Figure 2 shows the distribution of subjects and the frequency of subjects serum positive for ANAs categorised according to BMI. In the COPD group, those in the lowest BMI category $\left(<22 \mathrm{~kg} / \mathrm{m}^{2}\right)$ had a high chance of being serum positive for ANAs (figure 2D), but this was not the case for non-COPD controls (figure 2C). Figure $1 \mathrm{~B}$ shows that patients with COPD with low BMI had a significantly higher probability (0.11-1.56) of being ANA-positive than patients with normal BMI ( $\mathrm{p}=0.017)$; the OR for low BMI was 4.93 (95\% CI 1.50 to 16.15) (table 2).

Subjects with both COPD and a low BMI $(n=16)$ had a much higher risk of being ANA-positive than healthy subjects with normal BMI (OR 8.61, 95\% CI 2.21 to 33.59). For subjects with COPD and normal BMI ( $\mathrm{n}=68)$, no significant association was found with the presence of ANAs (OR 1.81, 95\% CI 0.66 to 4.94). However, this tendency towards an interaction between COPD and BMI was not significant in a logistic regression model $(p=0.273)$. In healthy subjects there was no difference between ANA serum levels for low BMI compared with normal BMI (OR 1.11).

\section{ANCAs and other autoantibodies}

ANCAs were measured in 46 patients with COPD and 8 nonCOPD controls and all samples were negative. Anti-mitochondrial, anti-smooth muscle, anti-parietal cell and anti-liver-kidney microsomal were measured in 12 patients with COPD and all samples were negative.

\section{Antibody repertoire of $B$ cells in the lung}

We examined the antibody repertoire sequences of $B$ cells in the lung in order to test for characteristics of self-reactivity: Selfreactive antibodies against DNA and nuclear targets (ANAs) have a high frequency of cationic residues in the hypervariable part of the heavy chain, the complementarity-determining region 3 (IgH-CDR3). ${ }^{21-23}$

First, IgH sequences of antibodies against nuclear antigens from published data were compared with non-self-reactive antibodies to quantify this characteristic for ANA reactivity. Antibodies from patients and control subjects were cloned, sequenced and the ANA reactivity for each monoclonal was tested by the HEp-2 assay. ${ }^{24} 25$ HEp2-reactive antibodies
Figure 1 Antinuclear antibodies (ANAs) in patients with chronic obstructive pulmonary disease (COPD) and healthy controls grouped by $(A)$ disease status and smoking history and (B) disease status and BMI. For each group the percentage of patients positive for ANAs is given.
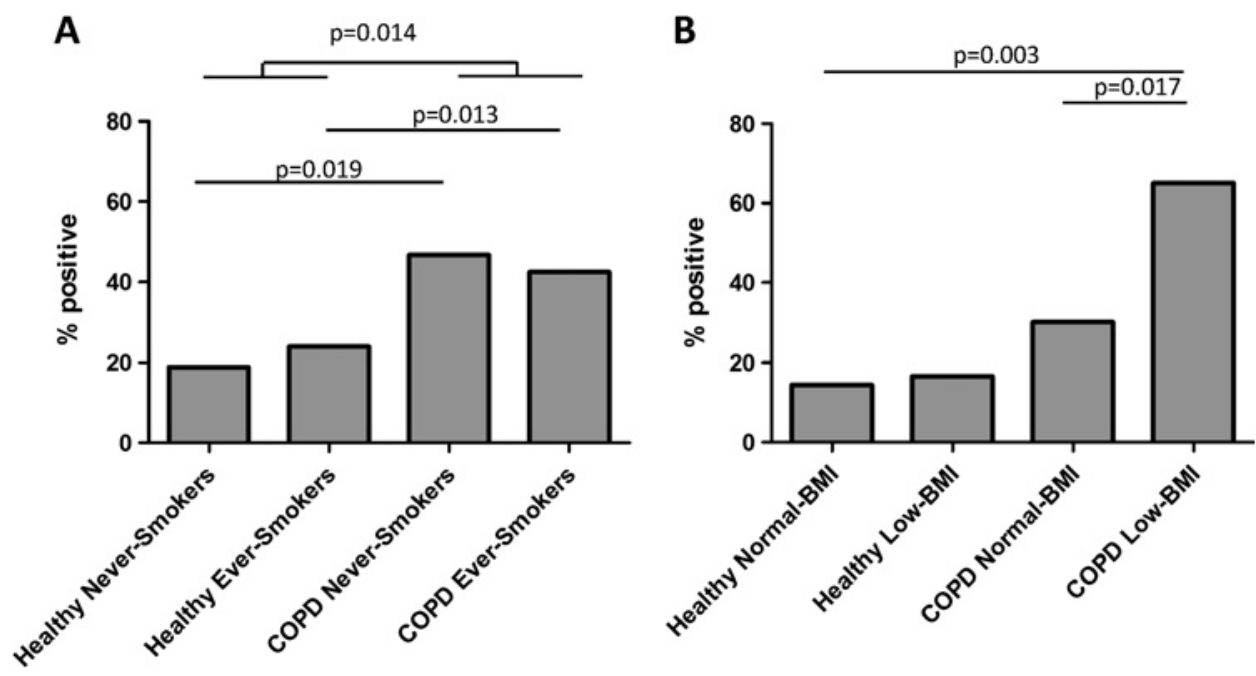
Table 2 Univariate and adjusted ORs for the presence of antinuclear antibodies

\begin{tabular}{|c|c|c|c|c|}
\hline \multirow[b]{2}{*}{ Total group } & \multicolumn{2}{|l|}{ Univariate } & \multicolumn{2}{|l|}{ Adjusted* $^{*}$} \\
\hline & OR $(95 \%$ CI) & p Value & $\overline{O R}(95 \% \mathrm{CI})$ & p Value \\
\hline Age (years) & 1.05 (1.02 to 1.08$)$ & 0.004 & 1.02 (0.98 to 1.06$)$ & 0.347 \\
\hline Gender (F/M) & 1.04 (0.61 to 1.79$)$ & 0.888 & 0.60 (0.26 to 1.42 ) & 0.245 \\
\hline COPD status (COPD/no COPD) & 2.69 (1.52 to 4.74$)$ & 0.001 & $3.12(1.68$ to 5.76$)$ & $<0.001$ \\
\hline \multicolumn{5}{|l|}{ Smoking status } \\
\hline Never & Reference & & Reference & \\
\hline Ex-smoking & 1.02 (0.52 to 2.03 ) & 0.950 & 1.82 (0.44 to 7.47$)$ & 0.405 \\
\hline Current smoking & 1.32 (0.66 to 2.64 ) & 0.427 & 2.06 (0.48 to 8.82$)$ & 0.329 \\
\hline Pack-years & 1.00 (0.99 to 1.01$)$ & 0.871 & 1.01 (0.98 to 1.03 ) & 0.688 \\
\hline $\mathrm{BMI}(<22 / \geq 22)$ & 3.56 (1.39 to 9.09$)$ & 0.008 & 3.63 (1.34 to 9.86$)$ & 0.011 \\
\hline \multicolumn{5}{|l|}{ COPD group } \\
\hline Age (years) & 1.03 (0.98 to 1.07$)$ & 0.230 & $0.97(0.90$ to 1.04$)$ & 0.361 \\
\hline Gender (F/M) & 0.97 (0.47 to 1.97$)$ & 0.925 & 0.49 (0.15 to 1.58$)$ & 0.230 \\
\hline $\mathrm{FEV}_{1} \%$ pred & 1.01 (1.00 to 1.03$)$ & 0.132 & $1.00(0.97$ to 1.03$)$ & 0.912 \\
\hline $\mathrm{FEV}_{1} / \mathrm{FVC}$ ratio (\%) & 0.99 (0.96 to 1.02$)$ & 0.449 & 0.98 (0.93 to 1.04$)$ & 0.536 \\
\hline \multicolumn{5}{|l|}{ Smoking status } \\
\hline Never & Reference & & Reference & \\
\hline Ex-smoking & $0.64(0.26$ to 1.61$)$ & 0.347 & 1.71 (0.16 to 18.32$)$ & 0.659 \\
\hline Current smoking & $1.14(0.45$ to 2.90$)$ & 0.778 & $2.63(0.24$ to 28.93$)$ & 0.430 \\
\hline Pack-years & 1.00 (0.98 to 1.01$)$ & 0.529 & 0.99 (0.96 to 1.03$)$ & 0.624 \\
\hline $\mathrm{BMI}(<22 / \geq 22)$ & $4.30(1.37$ to 13.47$)$ & 0.012 & $4.93(1.50$ to 16.15$)$ & 0.009 \\
\hline
\end{tabular}

$(n=166)$ contained, on average, $7.8 \%$ cationic residues in $\operatorname{IgH}-$ CDR3 while antibodies not directed against nuclear antigens $(n=265)$ only had $5.7 \%$ cationic residues $(p<0.021$, figure $3 D)$.

$\mathrm{B}$ cell aggregates were isolated by laser microdissection from lung sections of patients with COPD and non-COPD patients.
Table 3 shows the patient characteristics. The VDJ regions of the rearranged $\operatorname{IgH}$ alleles were amplified by $\mathrm{PCR}$, cloned and sequenced (figure 3A,B). In total, we found 138 unique CDR3 (protein) sequences, 79 of which were derived from patients with COPD and 59 from non-COPD controls. Lung B cell clones
Figure 2 Body mass index (BMI) distribution and antinuclear antibodies (ANAs) in patients with chronic obstructive pulmonary disease (COPD) and controls with normal lung function. Distribution of subjects stratified by BMI in (A) the control group $(n=61)$ and $(B)$ the COPD group $(n=84)$. Values are given as percentage of total subjects in each group. $(C, D)$ Percentage of ANApositive subjects within each category for (C) controls and (D) patients with COPD.
A

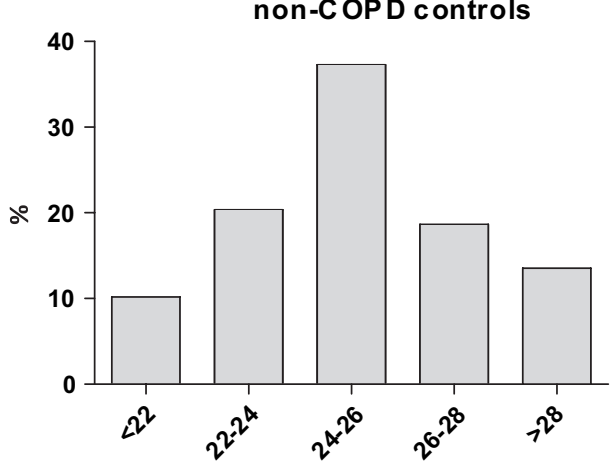

C

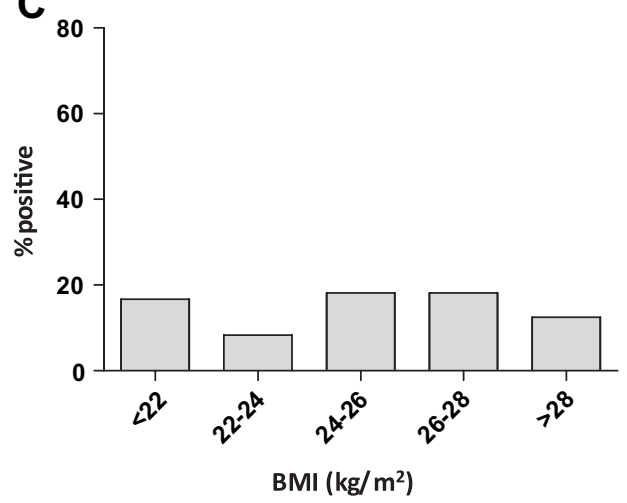

B



D




Figure $3 \mathrm{IgH}$ repertoire analysis of lung-infiltrated B cells. (A) B cell follicles in $20 \mu \mathrm{m}$ thick frozen lung sections were stained (CD20) and harvested by laser microdissection. (B) DNA was isolated and $\operatorname{lgH} \mathrm{CDR} 3$ regions were amplified in semi-nested PCR.

Oligonucleotides are shown by short arrows. The oligoclonal pool of CDR3 amplicons was then cloned individually in $E$ coli, sequenced and the amino acid composition of the CDR3 was determined. (C) Frequency of cationic amino acids (shown in \%) in the CDR3 region of antibodies sequenced from lung-infiltrated $B$ cells. Each dot represents the average values of $10-30$ antibodies from one patient.

(D) Frequency of cationic amino acids (shown in \%) in the CDR3 region of antibodies from Barbas et $a l^{19}$ and Wardemann et al. ${ }^{20}$ These were characterised for reactivity against antinuclear targets. Each represents the average value of $10-50$ antibodies from one subject.
A



C

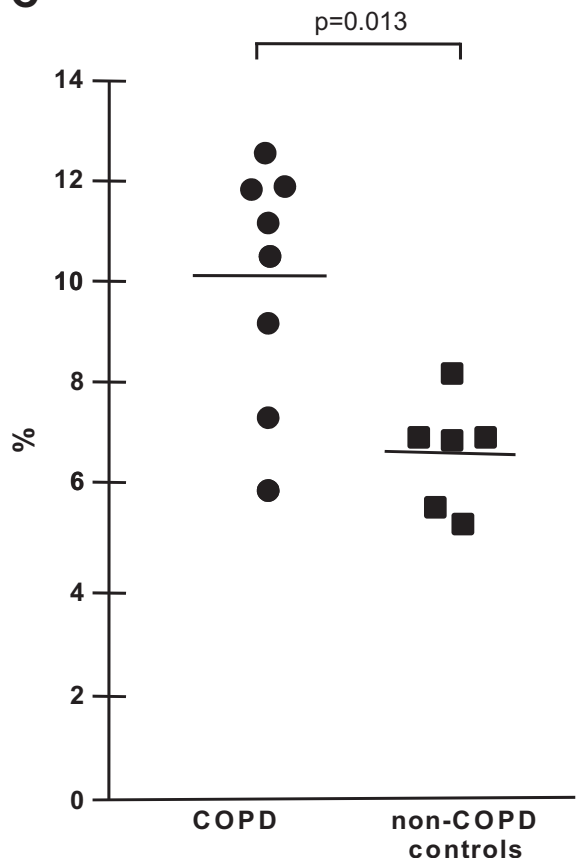

B
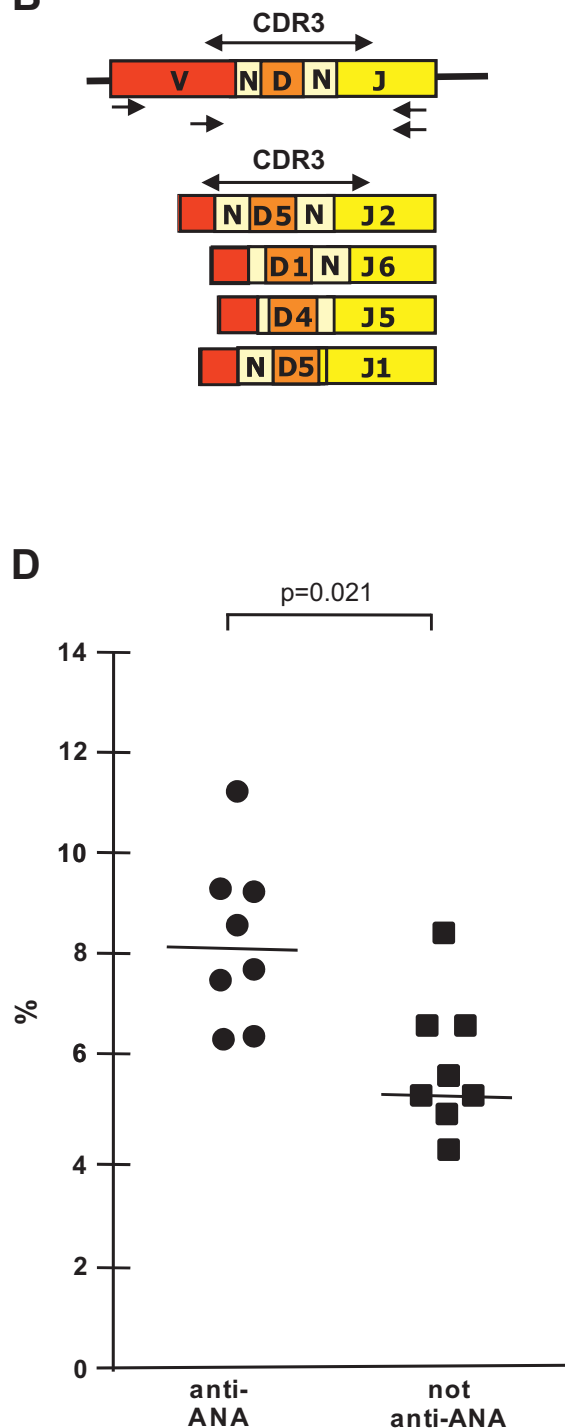

from patients had, on average, $10.0 \%$ cationic CDR3 residues which was significantly more than in non-COPD patients $(6.7 \%$, $\mathrm{p}<0.013$; figure $3 \mathrm{C}$ ).

\section{DISCUSSION}

It has been reported previously that a significant number of patients with COPD have antibodies against self-antigens but some apparently do not develop an autoimmune response. We

Table 3 Characteristics of patients and controls contributing surgical resection material

\begin{tabular}{lll}
\hline & COPD patients & Non-COPD controls \\
\hline Subjects (n) & 8 & 8 \\
Women (\%) & 62.5 & 62.5 \\
Age (years) & $55.4 \pm 5.7$ & $59.4 \pm 7.8$ \\
$\mathrm{FEV}_{1} \%$ pred & $35.0 \pm 24.8$ & $85.5 \pm 16.3$ \\
$\mathrm{FEV}_{1} / \mathrm{FVC}$ ratio (\%) & $36.6 \pm 8.8$ & $86.4 \pm 17.1$ \\
Ex/no smokers & $8 / 0$ & $4 / 4$ \\
Pack-years & $35.0 \pm 24.8$ & $12.2 \pm 14.0$
\end{tabular}

Number, average values and SDs are shown.

$\mathrm{FEV}_{1} \%$, forced expiratory volume in $1 \mathrm{~s}$ (\% predicted); FVC, forced vital capacity. have quantified the fraction of patients that are positive for ANAs and other autoantibodies, and investigated which characteristic of the patient population is associated with higher ANAs. We found that $44 \%$ of the patients with COPD were ANA-positive, significantly more than the prevalence of $22 \%$ in controls. The presence of ANAs was not associated with smoking behaviour. Among the patients with COPD, higher ANAs were more often found in patients with low BMI. Finally, we observed that the antibody repertoire of $B$ cells in the lungs of patients with COPD has a high frequency of positively charged CDR3 residues, a feature which is associated with selfreactive antibodies.

A significant group of patients with COPD has been reported to carry serum autoantibodies against elastin or antinuclear targets by three independent studies, ${ }^{7-9}$ whereas other reports have not shown an antibody response against elastin in patients with COPD. ${ }^{10}{ }^{11}$ Feghali-Bostwick and coworkers ${ }^{8}$ reported that $68 \%$ of 47 patients with COPD were serum positive for ANAs whereas Hodson and Turner-Warwick found $28 \%$ of 50 patients with severe chronic bronchitis to be serum positive for ANAs. ${ }^{7}$ Our study in a larger population of patients with COPD $(n=124)$ shows that $44 \%$ were ANA positive. Thus, although the sample sizes are small, all these studies show that a significant group of 
patients with COPD develops an autoimmune response against antinuclear targets. The clinical relevance should now be tested in larger cohorts.

It remains unclear how immune tolerance is broken in patients with COPD and autoimmunity against nuclear antigens arises. Our data on lung tissue suggest that lung B cells may play a role. We show for the first time that lung $B$ cells of patients with COPD produce antibodies that carry a high frequency of positively charged amino acids in the IgH-CDR3, a feature which is also observed with ANAs. We therefore hypothesise that the development of COPD is associated with infiltration of B cells in the lung that are directed at infectious material or residues of destroyed lung tissue. B cell follicular structures then arise in which germinal centres can develop, enabling B cell isotype switching and affinity maturation by somatic hypermutations. With ongoing smoking, long-term inflammation and increasing lung damage in COPD, inflammatory cells are exposed to nuclear antigens derived from damaged epithelial cells and probably many other antigenic protein residues of damaged cells and structures. $^{26} 27$ This exposure may last for years, even after smoking cessation, ${ }^{26}$ and can cause the unintended recognition of (nuclear) antigens by somatically hypermutated antibodies that were originally targeted to non-self antigens.

Our data thus suggest that B cells in the lungs of patients with COPD generate antibodies (or antibody receptors) which share a feature that is characteristic for ANAs-positively charged residues in the IgH CDR3 region, one of the regions in antibodies that is critical for antigen binding. Of interest, B cells present in the lungs of non-COPD patients have this characteristic significantly less frequently.

As smoking was found to be related to the prevalence of ANA in a large cohort study of the general (non-COPD) population ${ }^{12}$ and as COPD is recognised mostly as a smoking-related disease, one might expect that the autoantibody levels are related to smoking history in COPD as well. In our cohort of patients with COPD and controls we did not find such a relationship. This could be due to sample size limitations because we analysed only 232 subjects compared with 2875 subjects in the abovementioned cohort study. Furthermore, differences in study design and in genetic background (Caucasian vs Japanese) may have played a role.

Our findings support the hypothesis that the presence of autoantibodies is associated with COPD and not (or not only) with smoking per se. First, the presence of ANAs in patients with COPD was not associated with smoking history, smoking status or pack-years of smoking. Second, our group of nonsmoking patients with COPD had a significantly higher prevalence of ANAs than the non-smoking controls. It therefore seems likely that the increased presence of autoantibodies in COPD is also associated with the disease itself and is not only caused by smoking. As indicated above, this should be further validated by testing in a larger cohort of patients with COPD and controls.

Within the COPD study group we found no association of ANAs with lung function or with COPD stage as defined by GOLD criteria. This is in agreement with data reported previously $^{8}$ and suggests that an autoimmune response is associated with having developed COPD as such and not with the severity of the disease.

Interestingly, our study showed that the presence of ANAs was significantly associated with a low BMI. Patients with COPD with a BMI $<22 \mathrm{~kg} / \mathrm{m}^{2}$ had a 4.9 times higher probability of being ANA-positive whereas this was not the case in non-COPD controls. Thus, an association between COPD and autoimmunity occurs particularly in people with a low BMI. Although we only observed a significant positive association between a low BMI and the presence of ANAs in subjects with COPD (OR 4.3, 95\% CI 1.4 to 13.5) and not in subjects without COPD (OR 1.2, 95\% CI 0.1 to 11.4), we found no statistical proof of effect modification when an interaction term of COPD and low BMI was included in the logistic regression analysis. This is probably due to the low number of available subjects with low BMI, especially in the group without COPD $(n=6)$.

An autoantibody response has recently been associated with low BMI in patients with $\mathrm{COPD}{ }^{8}$ Using immunoprecipitation of antibodies purified from COPD patients with human cells, Feghali-Bostwick et al identified a $130 \mathrm{kD}$ autoantigen which was associated with low BMI in patients with COPD. ${ }^{8}$ It is possible that this $130 \mathrm{kd}$ autoantigen is a nuclear antigen which is also picked up in the ANA assay. This could partly explain why patients with COPD with low BMI are ANA-positive. A possible way to investigate this further is to isolate or clone antibodies from patients with COPD and test their reactivity against both antinuclear (eg, Hep-2 or antigen-specific nuclear targets) and $130 \mathrm{kD}$ and other proteins in immunoprecipitation assays. Second, our findings are interesting in view of a previous observation $^{28}$ that patients with COPD with a predominantly emphysematous phenotype (ie, low attenuation areas on the CT scan) had a significantly lower BMI range $\left(20.2 \pm 2.8 \mathrm{~kg} / \mathrm{m}^{2}\right)$ than patients with predominantly airway thickening $(23.0 \pm 2.6 \mathrm{~kg} /$ $\mathrm{m}^{2}$ ). It remains to be determined whether patients with COPD with a high percentage of low attenuation areas are also ANApositive. Together these data suggest an association between three characteristics shared by one specific group of patients with COPD: an emphysema-dominant phenotype, low BMI and self-reactivity against nuclear antigens.

Our findings may help to achieve a better understanding of the multifactorial and complex disorder of COPD and to divide this heterogeneous population into relevant phenotypes. Previous data suggested the existence of a patient subpopulation characterised by low BMI, an emphysema-dominant phenotype and an unidentified autoimmune response. Our data extend these observations and suggest that this subpopulation is associated with an autoimmune response against antinuclear targets and, additionally, that smoking behaviour and gender are not linked to this subpopulation. It will be interesting to determine whether the response to other autoantigens shares the same characteristics. Interestingly, even non-smoking individuals with lung function values compatible with COPD have increased levels of ANAs. None of these subjects had other complaints or clinical findings indicative of autoimmune disease. This suggests that either environmental tobacco smoke or other environmental factors or endogenous factors contribute to COPD development and that this is associated with elevated ANAs.

Funding This study was supported by a grant from the Dutch "Stichting Astma Bestrijding" and the Netherlands Asthma Foundation.

\section{Competing interests None.}

Ethics approval This study was conducted with the approval of the hospital medical ethical committees of Groningen and Cracow.

Provenance and peer review Not commissioned; externally peer reviewed.

\section{REFERENCES}

1. Mannino DM, Homa DM, Akinbami LJ, et al. Chronic obstructive pulmonary disease surveillance-United States, 1971-2000. MMWR Surveill Summ 2002;51:1-16.

2. Halbert RJ, Isonaka S, George D, et al. Interpreting COPD prevalence estimates: what is the true burden of disease? Chest 2003;123:1684-92. 
3. Gan W0, Man SFP, Senthilsel van A, et al. Association between chronic obstructive pulmonary disease and systemic inflammation: a systematic review and a metaanalysis. Thorax 2004;59:574-80.

4. Hogg JC, Chu F, Utokaparch S, et al. The nature of small-airway obstruction in chronic obstructive pulmonary disease. N Engl J Med 2004;350:2645-53.

5. Gosman MME, Willemse BWM, Jansen DF, et al. Increased number of B-cells in bronchial biopsies in COPD. Eur Respir J 2006;27:60-4.

6. van der Strate BWA, Postma DS, Brandsma CA, et al. Cigarette smoke-induced emphysema: a role for the B cell? Am J Respir Crit Care Med 2006:173:751-8.

7. Hodson ME, Turner-Warwick M. Autoantibodies in patients with chronic bronchitis. Br J Dis Chest 1976;70:83-8.

8. Feghali-Bostwick CA, Gadgil AS, Otterbein LE, et al. Autoantibodies in patients with chronic obstructive pulmonary disease. Am J Respir Crit Care Med 2008;177:156-63.

9. Lee SH, Goswami S, Grudo A, et al. Antielastin autoimmunity in tobacco smokinginduced emphysema. Nat Med 2007;13:567-9.

10. Greene CM, Low TB, O'Neill SJ, et al. Anti-proline-glycine-proline or antielastin autoantibodies are not evident in chronic inflammatory lung disease. Am J Respir Crit Care Med 2010;181:31-5.

11. Cottin V, Fabien N, Khouatra C et al. Anti-elastin autoantibodies are not present in combined pulmonary fibrosis and emphysema. Eur Respir J 2009;33:219-21.

12. Ishikawa M, Konta T, Hao Z, et al. Relationship between antinuclear antibody and microalbuminuria in the general population: the Takahata study. Clin Exp Nephrol 2008;12:200-6

13. van Straaten JFM, Coers W, Noordhoek JA, et al. Proteoglycan changes in the extracellular matrix of lung tissue from patients with pulmonary emphysema. Mod Pathol 1999;12:697-705.

14. Rabe KF, Hurd S, Anzueto A, et al. Global strategy for the diagnosis, management, and prevention of chronic obstructive pulmonary disease: GOLD executive summary. Am J Respir Crit Care Med 2007;176:532-55.

15. Kerkhof M, Droste JH, de Monchy JG, et al. Distribution of total serum lgE and specific IgE to common aeroallergens by sex and age, and their relationship to each other in a random sample of the Dutch general population aged 20-70 years. Dutch
ECRHS Group, European Community Respiratory Health Study. Allergy 1996:51:770-6.

16. Nizankowska-Mogilnicka E, Mejza F, Buist SA, et al. Prevalence of COPD and tobacco smoking in Malopolska region-results from the BOLD Study in Poland. Polskie Archiwum Medycyny Wewnetrznej 2007;117:402-9.

17. Rutgers S, Koeter DM, Postma DS. Protective effect of oral terfenadine and not inhaled ipratropium on adenosine $5^{\prime}$-monophosphate-induced bronchoconstriction in patients with COPD. Clin Exp Allergy 1999;29:1287-92.

18. Mulder L, Horst G, Haagsma EB et al. Prevalence and characterization of neutrophi cytoplasmic antibodies in autoimmune liver diseases. Hepatology 2005;17:411-17.

19. Franssen CF, Stegeman CA, Oost-Kort WW, et al. Determinants of renal outcome in anti-myeloperoxidase-associated necrotizing crescentic glomerulonephritis. J Am Soc Nephrol 1998;10:1915-23.

20. Giudicelli V, Chaume D, Lefranc MP. IMGT/N-QUEST, an integrated software program for immunoglobulin and T cell receptor V-J and V-D-J rearrangement analysis. Nucl Acids Res 2004;32(Suppl 2):W435-40.

21. Radic MZ, Weigert M. Genetic and structural evidence for antigen selection of antiDNA antibodies. Ann Rev Immunol 1994;12:487-520.

22. Barbas SM, Ditzel HJ, Salonen EM, et al. Human autoantibody recognition of DNA Proc Natl Acad Sci USA 1995:92:2529-33.

23. Wardemann H, Yurasov S, Schaefer A, et al. Predominant autoantibody production by early human B cell precursors. Science 2003;301:1374-7.

24. Yurasov S, Wardemann $\mathrm{H}$, Hammersen J, et al. Defective B cell tolerance checkpoints in systemic lupus erythematosus. J Exp Med 2005;201:703-11.

25. Samuels J, $\mathrm{Ng}$ Y-S, Coupillaud C, et al. Impaired early B cell tolerance in patients with rheumatoid arthritis. J Exp Med 2005:201:1659-67.

26. Hodge S, Hodge G, Holmes M, et al. Increased airway epithelial and T-cell apoptosis in COPD remains despite smoking cessation. Eur Respir J 2005;25:447-54.

27. Taraseviciene-Stewart L, Voelkel NF. Molecular pathogenesis of emphysema. J Clin Invest 2008;118:394-402.

28. Ogawa $\mathbf{E}$, Nakano $Y$, Ohara $T$, et al. Body mass index in male patients with chronic obstructive pulmonary disease; correlation with low attenuation areas on CT. Thorax 2009:64:20-5

\section{Lung alert}

\section{No sedation in mechanical ventilation is associated with increased ventilator-free days}

Disadvantages of sedation in intensive care include prolonged ventilation, delirium and difficulties in mental status assessment. Previous studies comparing bolus sedation with continuous sedation have demonstrated a reduced duration of mechanical ventilation with boluses.

In this study 140 critically ill patients undergoing mechanical ventilation were randomised in a 1:1 ratio to receive no sedation or standardised sedation with propofol/midazolam and daily awakening. The groups were similar phenotypically. Both groups were treated with bolus dose morphine for comfort. Patients receiving no sedation had more ventilator-free days (mean difference 4.2 days). The same patients also had shorter stays in intensive care (HR 1.86). There was no significant difference in mortality between groups in the occurrence of complications or need for tracheostomy. However, incidents of delirium were higher in the no sedation group ( $20 \%$ vs $7 \%$ ), as was the use of haloperidol. $18 \%$ of patients in the no sedation group did not tolerate the intervention.

This single-centre study concludes that sedation-free ventilation is associated with shorter periods of ventilation with no increase in short-term complications. It remains to be seen if the incidence of post-traumatic stress disorder syndrome is higher in these patients. The authors plan a 1 year review.

Strøm T, Martinussen T, Toft P. A protocol of no sedation for critically ill patients receiving mechanical ventilation: a randomised trial. Lancet 2010;375:475-80

\section{Z Puthucheary}

Correspondence to Z Puthucheary, Clinical Lecturer, Institute of Health and Human Performance, University College London, London N19 5LW, UK; zudin.puthucheary.09@ucl.ac.uk

Published Online First 14 October 2010

Thorax 2011;66:107. doi:10.1136/thx.2010.145615 